\title{
On the analysis of Catalan thin vaults
}

\author{
S. Benfratello, L. Palizzolo, F. Giambanco \& M. D’Avenia \\ Department of Structural and Aerospace Engineering and Geotechnics \\ (DISAG), University of Palermo, Italy
}

\begin{abstract}
This paper is concerned with the identification, modelling and analysis of thin layered vaults, typical in the Catalan constructions of the XIX century. These special structures, also known as bòvedas tabicadas, are characterized by very low thickness with respect to the medium surface dimensions and by the presence of different superimposed layers of bricks tied with mortar, are studied in order to individuate a coherent mechanical model for describing the material behaviour, to recognize the structural response utilizing as comparison adequate experimental results, and to extend the obtained results for the analysis of new vaults or for the restoration design of existing vaults. Firstly, the constitutive material is studied by effecting a compression and bending test on samples taken from a real structure. The characterization is made by considering alternatively the material as homogeneous or stratified. Once the constitutive behaviour of the materials and of the structural elements has been experimentally characterized, a semi inverse method for the identification of the optimum mechanical parameters of an equivalent homogeneous ideal material and of a stratified one, is adopted on the grounds of finite element analysis, reproducing the executed experimental tests. The comparison between the results obtained experimentally and the ones based on numerical tests allows us to make evaluations on the mechanical characteristics of the identified materials and proves that the stratified model better describes the behaviour of the real material. Further experimental tests have been made on a real vault and the related numerical analysis has developed making reference to the two material mechanical models. The obtained results are encouraging in the utilization of the stratified model.
\end{abstract}

Keywords: thin vaults, material mechanical modelling, experimental and numerical analysis, restoration design. 


\section{Introduction}

For many years it has been recognized that both the restoration and reutilization culture of ancient buildings plays an increasing role in the design approach to historical centres. This role is due to the saturation of building zones, as well as to the cultural rediscovery of ancient buildings and of their social and cultural role. It is important to emphasize that these ancient buildings are usually characterized by constructional techniques peculiar to local traditions. As a consequence, technicians and researchers focused their attention on the structural analysis of such buildings by means of modern experimental and computational instruments, allowing very deep investigations. In this ambit the work presented in this paper can be framed. In particular, in this paper the experimental analysis and the structural modelling of thin vaults, known as bòvedas tabicadas (Figure 1), is presented (see, e.g., [1-4].

Such particular structures were widely adopted in Cataluña during the XIX century thanks to famous architects such as, among others, Raphael Guastavino, Antony Gaudì and Luis Moya Blanco (Figure 2).

The technique of Catalan vaulting possesses some peculiar characteristics related to the presence of particular quick-setting mortars, as well as to the high carrying capacity that such vaulting systems exhibit, also depending on their form, which guarantees a great resistance with respect to their small thickness. They can be synthetically described as curvilinear elements constituted by a succession of "rasillas" layers (usually variable between two and four layers), represented by tiles characterized by the ordinary dimensions of $15 \times 30 \times 1.5 \mathrm{~cm}$, laid down flat, and bulwarks along the first layer (said "sencillo") with chalk pasta, and with mortar of cement and lime in the following layers ("doblado").

In other papers, the authors have already introduced some studies related to the characterization of the behaviour of these structures on the grounds of suitable experimental tests executed on the materials of which they are constituted, as well as on some still existing vaulted structures. In particular, the constitutive behaviour of the materials and of the structural elements was

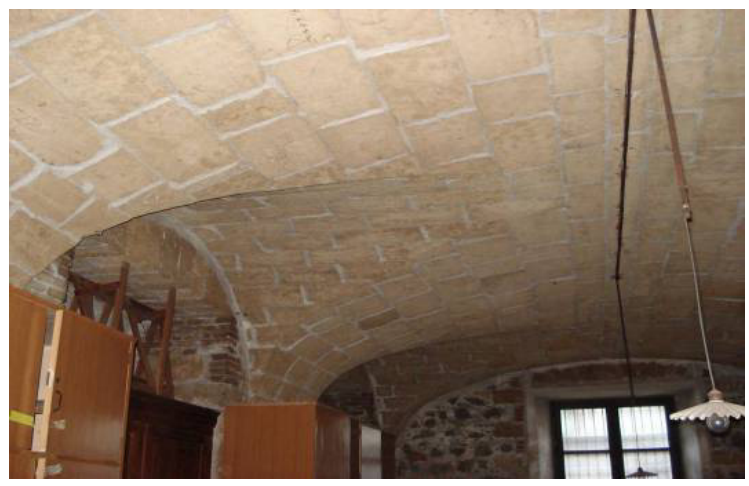

Figure 1: $\quad$ Typical Catalan vaulting. 

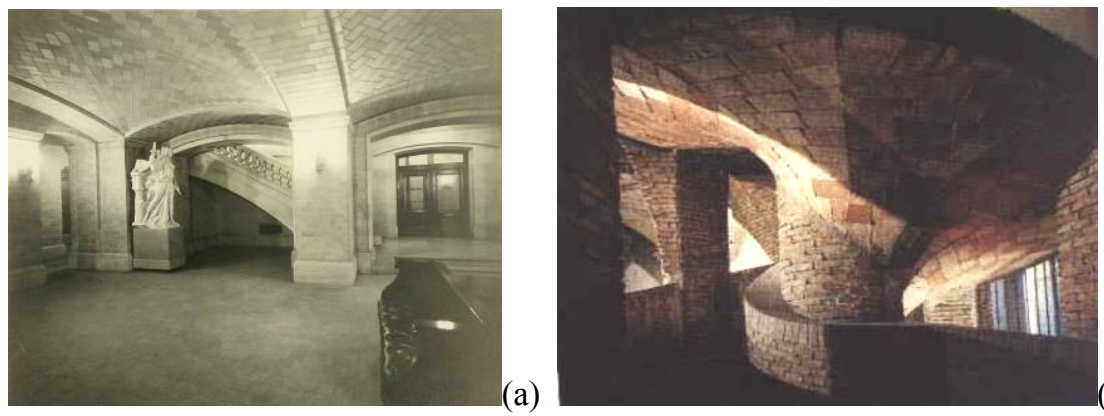

(b)
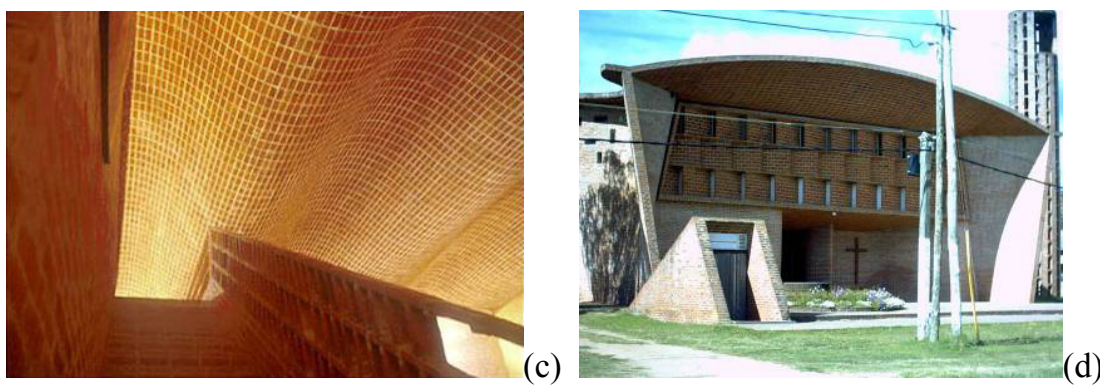

Figure 2: $\quad$ Guastavino (a), Gaudì (b) and Dieste (c-d) vaulting structures.

experimentally characterized, and subsequently a semi inverse method was utilized in order to identify the optimum mechanical parameters to assign to an equivalent homogeneous ideal material, through analysis reproducing the executed experimental tests, on the grounds of some appropriate finite element analysis.

The obtained and proposed modelling, although appropriate enough, can be improved by considering the real layered nature of the material. So, further experimental tests have been performed on the bricks and on the mortar, and appropriate numerical computations have been employed with the aim of obtaining a better identification of the real material.

The new results are compared with the previous ones and are utilized in the computation of a real vault, confirming the obtained improvement linked to the utilization of a stratified model instead of an ideal homogeneous one.

\section{Experimental results and material modelling}

The first step of study, necessary in order to interpret the whole structural behaviour, is related with the definition of a suitable mechanical model able to represent the material behaviour. To that end it is necessary to perform an experimental campaign in order to determine the main properties of the material to be considered in the mechanical model. Clearly, the particular typology of the material under examination requires the experimental analysis of both brick and mortar separately taken, as well as that of a representative portion of the layered 
material. Authors collected some samples taken from a building of the historic centre of Palermo, where some structural elements, mainly constituting walls, are made with the same technique of the "bòvedas tabicadas". The typical element is constituted by three layers of bricks with mean dimensions $26 \times 13 \times 2 \mathrm{~cm}$ connected by mortar of lime and plaster. From these samples, the following items required for experimental analysis have been derived: a) one masonry unit with dimension $32.25 \times 32.15 \times 11.50 \mathrm{~cm}$, to be tested under compression parallel to the layers in order to characterize the masonry compression behaviour; b) two masonry units with dimensions $37 \times 101 \times 11 \mathrm{~cm}$ to be tested under three and fourpoint bending in order to characterize the flexural masonry behaviour; c) six masonry cube specimen of mean dimensions equal to $12 \mathrm{~cm}$ to be tested under compression both parallel and orthogonal to the layer in order to characterize the role of the mortar in the layered material; d) three brick sample of mean dimensions of $2 \mathrm{~cm}$ to be tested under compression in order to characterize the brick characteristics; e) three bricks to be tested under a three point bending test in order to characterize the mean tensile strength of the brick. In order to identify the main characteristics of the mortar some samples have been collected and are still under petrographic and chemical investigations. All the mechanical tests together with the petrographic one have been performed at the Laboratory of the Department of Structural and Aerospace Engineering and Geotechnics of the University of Palermo, while the chemical ones are performed at Chemical Engineering Department of the University of Palermo.

Once the experimental results have been collected, the second step has been that of identifying the mechanical model of the mortar by numerically reproducing the compression and the bending tests on the ground of finite element analysis by utilizing the program ADINA 8.6.1. In section 3 all the results will be adopted for the numerical analysis of a real structure by comparing the experimental results with those arising from the numerical analysis both in the case of a homogeneous material as well as of a layered material.

In the following sections the results of both experimental tests and of the numerical analysis will be reported.

\subsection{Experimental results}

\subsubsection{Compression and bending tests on a masonry unit}

The compression test on a masonry unit parallel to the layers (further details in $[5,6])$ has been effected on a sample with dimensions $32.25 \times 32.15 \times 11.50 \mathrm{~cm}$ (Figure 3). The obtained results, in terms of stress and strain, are plotted in Figure 4. As it is possible to observe, the sample exhibits at first a linear elastic behaviour until a stress of $2.6 \mathrm{MPa}$ value, with a tangent elastic modulus value at 1.7 GPa. Above such a limit stress, when the fractures began to manifest themselves, the sample exhibits the ability to resist to a stress nearly constant with restricted pseudoplastic deformations. This behaviour is followed by the onset of new and greater fractures related with a decreasing of the resistance of the sample until its definitive collapse. 

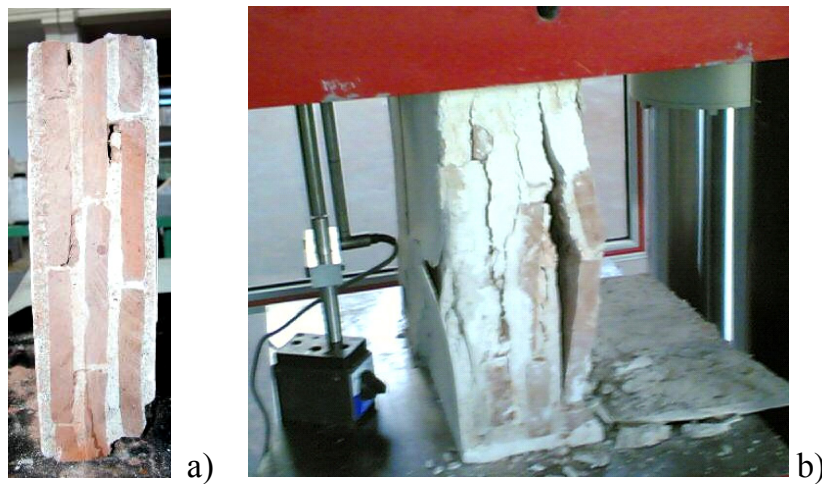

Figure 3: Compression test on a masonry unit parallel to the layer: a) sample; b) sample fracture.

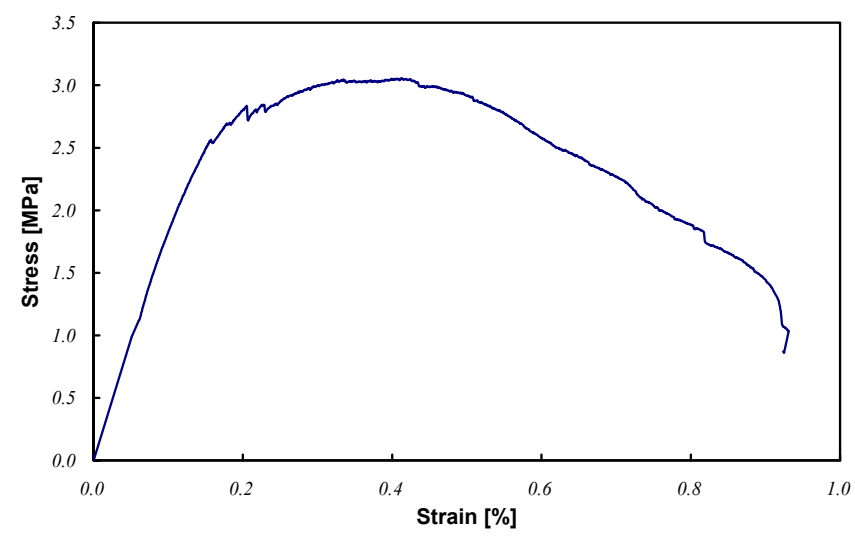

Figure 4: Stress-strain diagram deduced by the compression test.

Other two samples, collected by the same wall, have been put to three-point and four-point bending tests. For brevity's sake in Figures 5 only the test engine, scheme and results (in terms of load-displacement) for the four-point bending test are reported.

\subsubsection{Compression test on the masonry specimen}

In order to characterize the mechanical properties of the mortar, three masonry specimens of mean dimensions equal to $12 \mathrm{~cm}$ have been tested under compression parallel to the layers and other three under compression orthogonal to the layers. In Figures 6 the investigated sample, the sample during and at the end of the test together with the results in terms of stress-strain are reported for the compression test parallel to the layers. In Figure 7 the same quantities are reported for the case of compression test orthogonal to the layers. 
a)
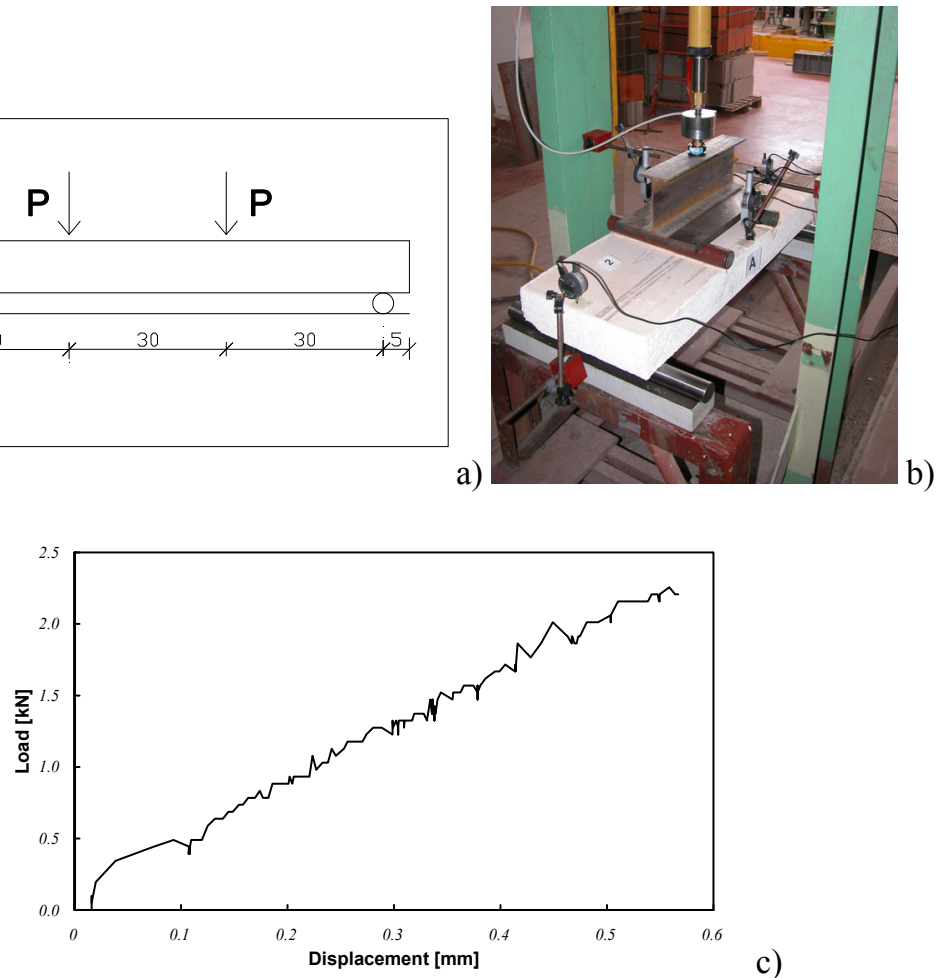

c)

Figure 5: Four-point bending test: a) test engine; b) test scheme; c) test results.

\subsubsection{Three-point bending test on masonry brick}

In order to characterize the tensile strength of the brick a three point bending test has been performed on three different bricks collected by the same samples described in the foregoing sections. In Figure 8 one of the brick and the test engine are reported. The obtained results give a mean tensile strength equal to 6 $\mathrm{MPa}$.

\subsubsection{Compression test on masonry brick}

In order to characterize the main mechanical characteristic of the bricks, i.e. its compression limit resistance and its elastic modulus, three appropriate cube specimens of mean dimension equal to $2 \mathrm{~cm}$ have been derived from a brick collected from the masonry sample. In Figures 9 one of the investigated sample together with the results in terms of stress-strain are reported.

\subsection{Material modelling}

As above mentioned, the second fundamental step is that to characterize the material characteristics. To this aim two different strategies have been employed: 

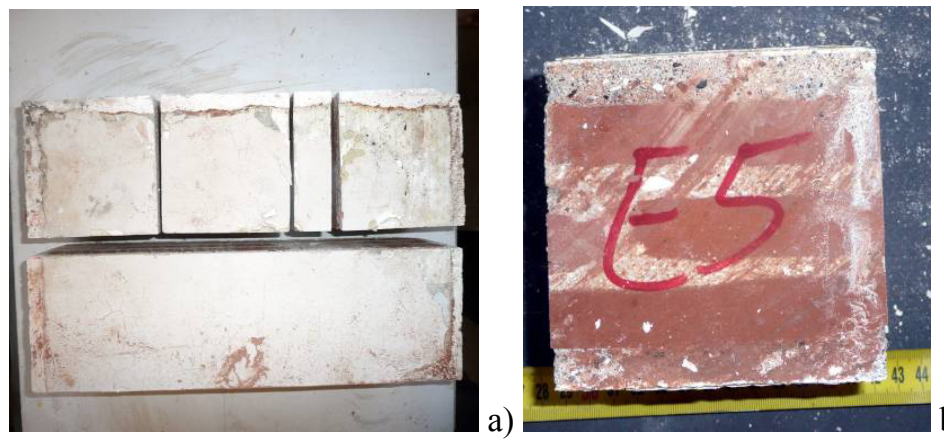

b)
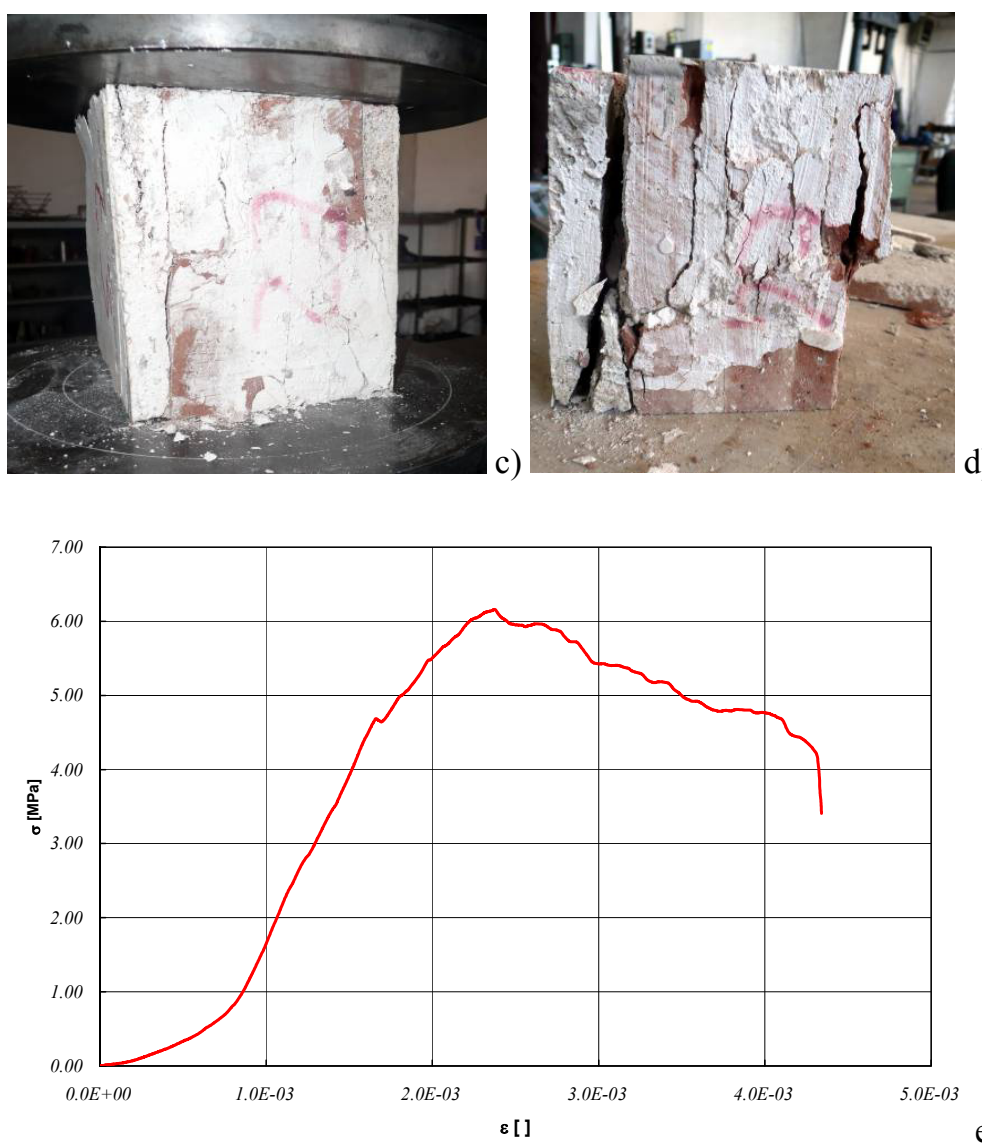

e)

Figure 6: Compression test parallel to the layers: a) original samples; b) particular of one sample; c) sample under the test; d) sample at the end of the test; e) results in terms of stress-strain. 
460 High Performance Structures and Materials V
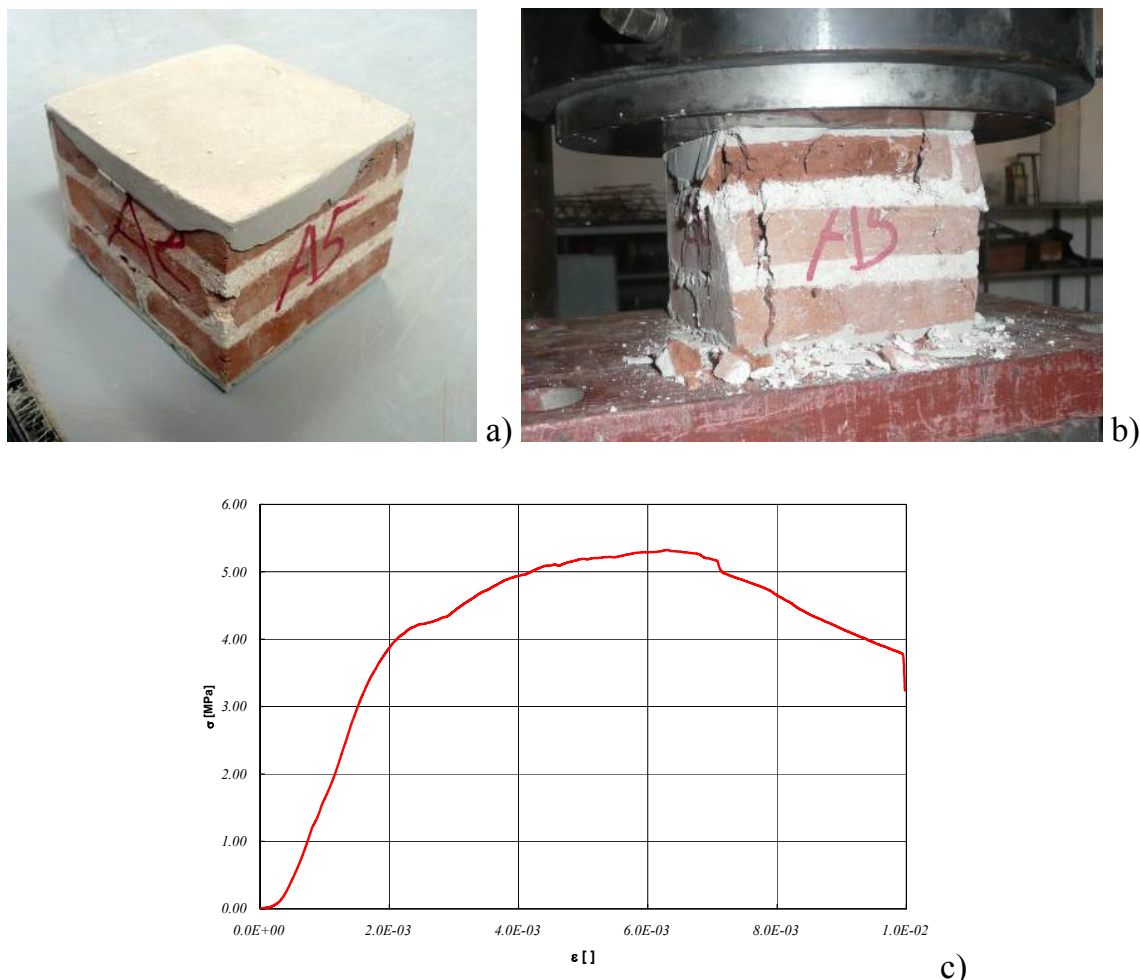

c)

Figure 7: Compression test orthogonal to the layers: a) sample; b) sample at the end of the test; c) results in terms of stress-strain.
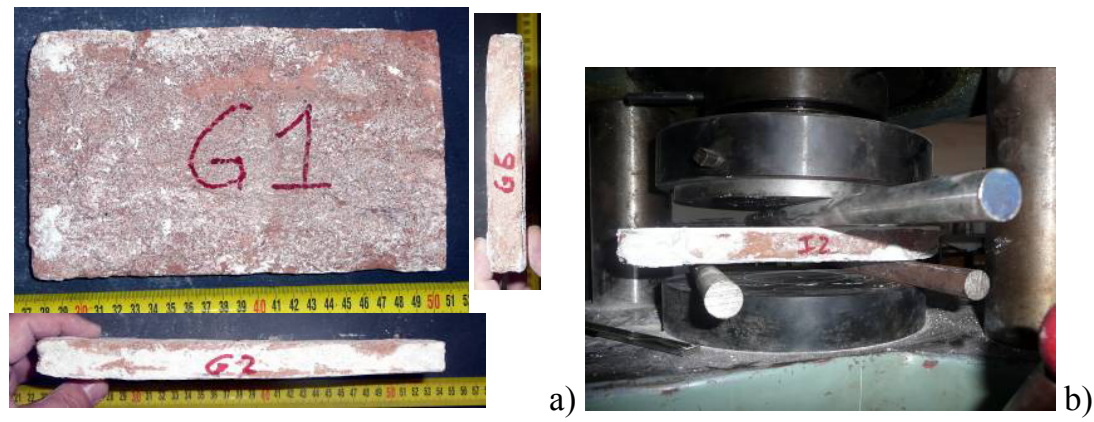

Figure 8: Three-point bending test on masonry brick: a) sample; b) test engine. 

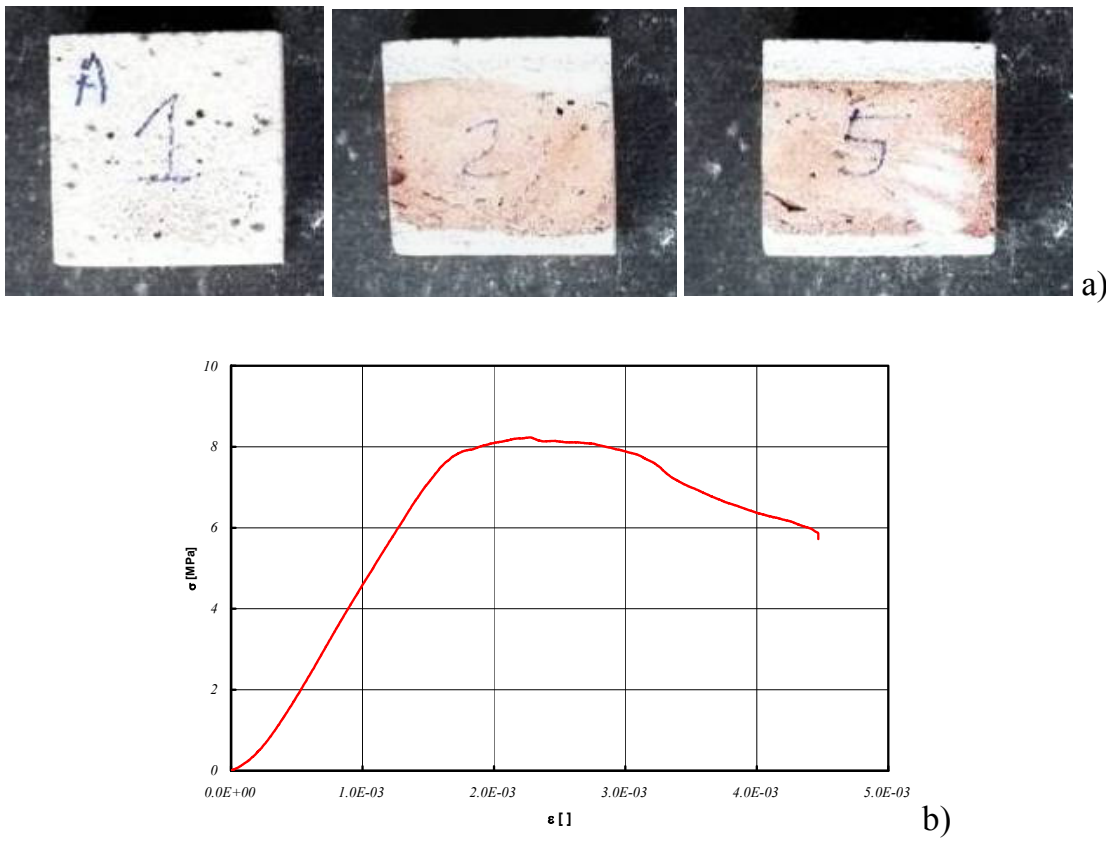

Figure 9: Compression test on masonry brick: a) samples; b) test results.

the first one is that to adopt a homogeneous ideal material and this study has already been effected and reported in [5-6]; the second one, proposed in the present paper is that of reproducing each layer as a homogeneous material with peculiar characteristics. In particular, the fundamental aim is to identify the role and the influence that from a mechanical point of view the mortar plays in the brick layers. To this end, the bending tests of masonry units and those regarding the compression tests parallel and orthogonal to the layers have been reproduced analytically by utilizing the program ADINA 8.6.1. Furthermore, the "concrete" model, present in ADINA library, and a four node element have been adopted for each layer identifying the brick parameters by means of the results obtained by the compression test and those of the mortar by means of a semi-inverse method. For the sake of brevity in Figures 10, the comparison between the obtained results is reported for the four point bending test. An examination of this figure shows the improvement in the results when the material is correctly modelled as a layered one.

It is worth noticing that the improvement of the results, with respect to the ones obtained in [5-6], is a consequence of several new experimental tests effected and of the more reliable information deduced. 

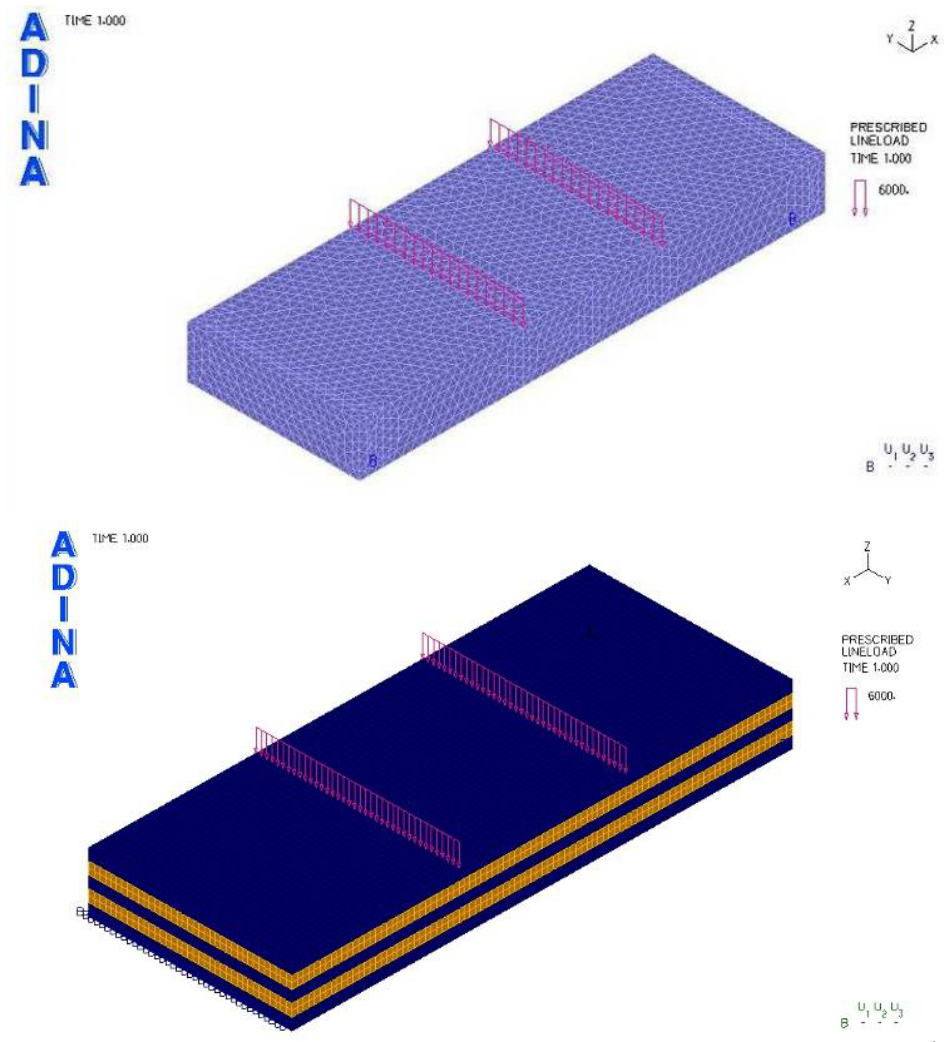

a)

b)

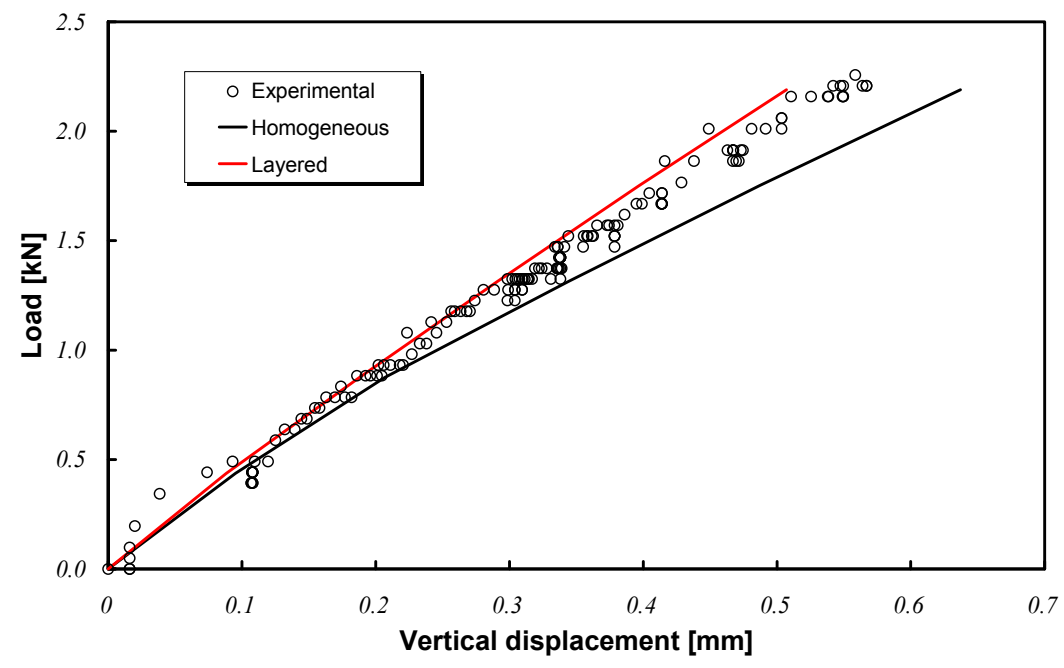

c)

Figure 10: Bending test numerical model: a) homogeneous material; b) layered material; c) comparison with experimental results. 


\section{Experimental results and vault numerical analysis}

Once the material behaviour has been identified and correctly modelled in numerical way, the structural behaviour of a real vault (Figure 11a,b) has been investigated experimentally as well as numerically. Further details on the experimental setup are reported in [5-6]. By experimental test the vertical displacements of three points (Figure 11a) due to a distributed load (ranging from 0.0 to $4.0 \mathrm{kN} / \mathrm{m}^{2}$ ) have been measured. The vault has been numerically modelled in two different ways: a) by adopting an homogeneous "concrete" material, four node elements and considering the real thickness in the geometry; b) by adopting four node shell elements with seven layers with linear elastic materials and considering the midsurface of the vault as geometry. The choice of linear elastic material is due to the facts that the concrete material cannot be used with shell layered elements and that the experimental results showed a linear behaviour. In Figure 12 the numerical model of the structure is reported and in Table 1 the comparison between the experimental results and those arising from the two numerical models are reported. From an examination of this table it can be recognized the improvement in the results by adopting a layered model of the material.
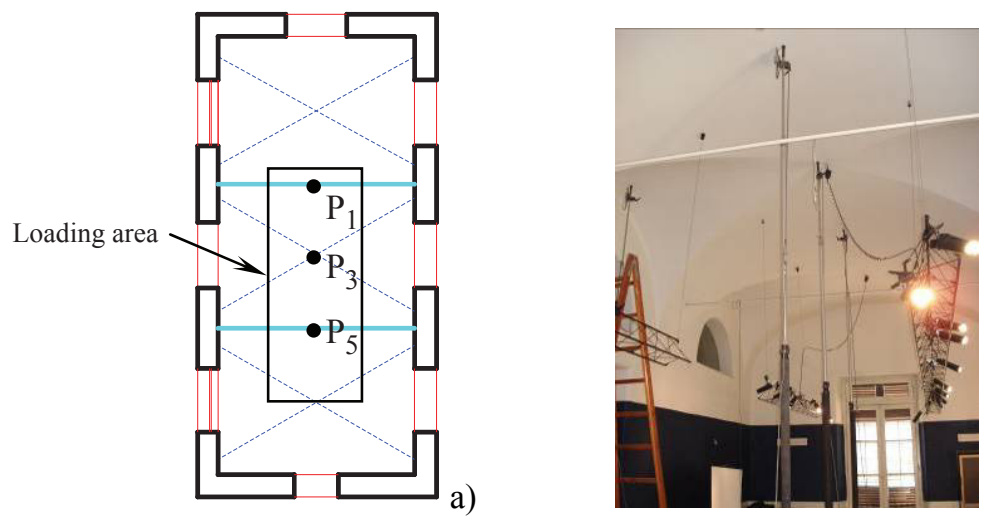

b)

Figure 11: a) Sketch of the vault plan; b) photo of the vault.

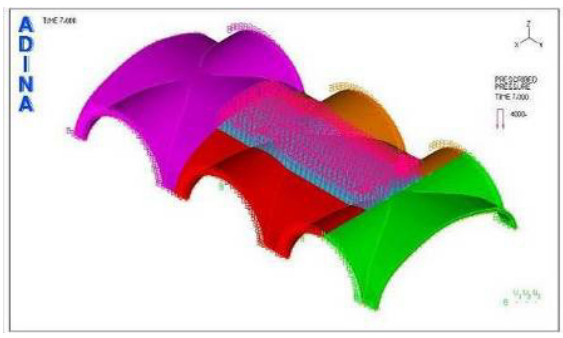

Figure 12: Numerical model of the vault reported in figure 11. 
Table 1: Comparison between experimental and numerical analysis (in $\mathrm{mm})$.

\begin{tabular}{|c|c|c|c|}
\hline & Experimental & $\begin{array}{c}\text { homogeneous } \\
\text { material model }\end{array}$ & $\begin{array}{c}\text { layered material } \\
\text { model }\end{array}$ \\
\hline $\mathrm{P}_{1}$ & 0.627 & 1.043 & 0.652 \\
\hline $\mathrm{P}_{3}$ & 0.911 & 1.890 & 1.280 \\
\hline $\mathrm{P}_{5}$ & 0.784 & 1.340 & 0.870 \\
\hline
\end{tabular}

\section{Conclusions}

The present paper has been devoted to some advance in the study of Catalan thin vaults, known as "bòvedas tabicadas", in order to improve the knowledge of their mechanical features and behaviour through new experimental and numerical procedures. In particular, suitable compression and bending experimental tests have been effected on the material, either on the layered block, with the aim of deduce mechanical characteristics of an ideal equivalent homogeneous material, or on the single constituent materials, i.e. tiles and mortar, with the aim of identifying the behaviour of an appropriate stratified model. In both cases, the experimental results have been utilized as comparison with the numerical results obtained for the utilized models by a finite element approach. Furthermore, the results obtained by some experimental tests effected on a real vault have been reported, and the same vault has been numerically analysed by utilizing alternatively the defined ideal equivalent homogeneous material and the stratified model. The numerical results showed that the stratified model better describes and interprets the behaviour of the real material and, as a consequence, of the whole structure.

\section{References}

[1] Guastavino Moreno, R., Essay on the theory and history of cohesive construction, applied especially to the timber vault, 2a Ed. Boston: Ticknor and Co., 1893.

[2] Moya Blanco, L., Bovedas tabicadas, Madrid: Colegio oficial de arquitectos de Madrid, 1993. Ripr.facs. dell'ed: Ministerio de la gobernacion, 1947.

[3] Gulli, R., Mochi, G., Il recupero delle volte in foglio attraverso la costruzione tabicada. Costruire in laterizio. Architetture voltate, 82; pp. 66$73,2001$.

[4] Viollet Le Duc, E., L'architettura ragionata, Ed. Jaca Book, 2002.

[5] Benfratello, S., Caffarelli, A., Palizzolo, L., Giambanco, F., Urso, R., Analisi numerica e sperimentale sul comportamento meccanico delle volte catalane, In: Sperimentazione06, ed. Russo S. \& Siviero E., pp. 269-278, 2006.

[6] Palizzolo L., Benfratello S., Caffarelli A., Giambanco F., Urso R., Bòvedas tabicadas: experimental and numerical analysis. In: High Performance Structures and Materials IV. Algarve (Portogallo), Southampton: WIT Press, pp. 503-512, 2008. 